\title{
Psicanálise, Plantão Psicológico e a Atuação em Âmbito Educacional
}

\author{
Maria Rita Alves Dalledone ${ }^{1}$ (D) , Natalia Leoni Michels ${ }^{2}$ (D), \\ Allan Martins Mohr ${ }^{3}$
}

FAE Centro Universitário - FAE, Curitiba, PR, Brasil

\begin{abstract}
Resumo: $O$ presente trabalho visa discutir brevemente as possibilidades de atuação profissional pelo exercício da psicanálise em moldes característicos de plantão psicológico. Sabe-se que, de princípio, o plantão fora criado com o intuito de suprir as altas demandas sociais de atenção em saúde mental, consiste em um atendimento emergencial, adaptado à demanda apresentada, e comprometido com o acolhimento do indivíduo no momento de crise. A psicanálise, por sua vez, possui método, técnica e arcabouço teórico que apresentam empasses para uma atuação que foge da clássica apresentada por Freud. Entretanto, em Lacan e em alguns textos do próprio pai da psicanálise, encontra-se a viabilidade de uma atuação comprometida com a função do analista e seu método para além do clichê técnico. A experiência dos autores com o atendimento de plantão psicológico numa Instituição de Ensino Superior embasou a pesquisa e a fundamentação do trabalho, tanto na teoria quanto na prática. Portanto, a pergunta que sustenta o artigo é relacionada ao desafio teórico-metodológico da atuação dos próprios autores: é possível propor um trabalho em psicanálise no formato de atendimento em plantão psicológico, em uma instituição educacional?
\end{abstract}

Palavras-chave: plantão psicológico, psicanálise, psicologia escolar/educacional

\section{Psychoanalysis, Psychological Emergency and Urgent Care and Educational Activities}

\begin{abstract}
The present work aims to briefly discuss the possibilities of professional performance through the exercise of psychoanalysis on psychological emergency care. It is known that, on principle, the emergency care assistance was created in order to meet the high social demands of mental health, it consists of urgency attendance, adapted to the demand presented, and committed to care for the individual in times of crisis. Psychoanalysis, on the other hand, has method, technique and theoretical framework that present impasses for a performance that differs from the classic one presented by Freud. However, in Lacan, and in some texts from the father of psychoanalysis, one finds the viability of a performance committed to the function of the analyst and his method, beyond the technical cliché. The authors' experience with psychological assistance at a Higher Education Institution based the research and foundations of the work, both in theory and at practice. Therefore, the question that supports the article is related to the theoretical-methodological challenge of the authors' own performance: is it possible to propose caring on psychological duty as a format for work in psychoanalysis, in an educational institution?
\end{abstract}

Keywords: psychological emergency care, psychoanalysis, educational psychology

1 Graduada em Administração e graduanda em Psicologia pela FAE Centro Universitário, Curitiba, Paraná, Brasil. E-mail: mrdalledone@gmail.com

2 Graduanda em Psicologia pela FAE Centro Universitário, Curitiba, Paraná, Brasil.E-mail: natalial.michels@gmail.com

3 Psicólogo, doutor em Filosofia. Psicólogo da Universidade Tecnológica Federal do Paraná, Câmpus Curitiba, e professor do Curso de Psicologia da FAE Centro Universitário, Curitiba, Paraná, Brasil. E-mail: allan.mohr@gmail.com

Submetido em: 26/10/2020. Primeira decisão editorial: 16/11/2020. Aceito em: 26/11/2020. 


\section{Introdução}

É um fato já bem descrito na literatura que o plantão psicológico surge como uma alternativa para os instrumentos sociais de atendimento psicológico que recebem demandas volumosas, mas que por vezes contam com pouca capacidade de atendimento. Não obstante, cabe dizer de partida que, mesmo com sua distinção, o atendimento de plantão é embasado na ética como compromisso de escuta, de cuidado, e se refere principalmente a um espaço de acolhimento. Sendo um espaço de escuta que muitas vezes ocorre em um único encontro, o que nos propomos por ora discutir é a possível técnica a ser utilizada, a teoria que a embasa e o método que a sustenta. Então, se nos for possível constituir um problema de pesquisa desde essa relação, temos: como fazer um atendimento em plantão psicológico de forma que decorra dele um efeito terapêutico? Ou, ainda, como problema anterior: o que se espera de um atendimento de plantão, que pode ocorrer em apenas um encontro? Para além dessas questões circunscritas à técnica, problematizamos: como encaixar uma "abordagem psicológica", como a psicanálise, com todas as aspas possíveis, no significante abordagem psicológica, em um atendimento do tipo plantão?

É em decorrência do aumento da demanda por atendimentos psicológicos em espaços que não possuem a capacidade e/ou competência de oferecer terapia convencional que entendemos a necessidade de discussão acerca da referida prática e de seus efeitos. Todavia, para além da importância científica, o tema é de particular relevância para os autores, uma vez que todos já atuaram em plantão psicológico oferecido por uma Instituição de Ensino Superior (IES). O que ora desejamos estudar, portanto, é a tese de que a psicanálise pode sim ser utilizada como arcabouço teórico, técnico e metodológico para um plantão psicológico; mais especificamente, em uma Instituição de Ensino Superior a partir de um trabalho de atendimento em psicologia escolar/educacional falaremos disso adiante.

Desta forma, a pergunta que motivou os autores pode ser assim escrita: é possível propor um trabalho em psicanálise no formato de atendimento em plantão psicológico, em uma instituição educacional? É a partir disso que o presente artigo se propõe a discutir sucintamente o que se têm na literatura sobre plantão psicológico, além de explorar a tese da possibilidade de uma psicanálise aplicada a uma proposta de atendimento em plantão.

De partida, ainda é mister ressaltar que a IES a qual embasou a experiência dos pesquisadores conta com cursos técnicos e ensino superior, oferecendo diversos cursos de Bacharelado, Licenciatura e Tecnólogo, assim como Mestrado e Doutorado. A instituição possui um Núcleo de Acompanhamento discente desde 2008, o qual disponibiliza acompanhamento psicológico e pedagógico, atendimento médico e odontológico, serviço social e auxílio estudantil, além de apoio aos estudantes com necessidades educacionais especiais. É nesse contexto que os autores deste artigo atuaram em plantão psicológico com a psicanálise. Plantão que se traduz em horários disponíveis para a escuta dos estudantes sem hora marcada, sem tempo fixado ou quantidade máxima de atendimentos.

A partir, então, dessas questões, propusemos o presente artigo desenvolvido da seguinte maneira: inicialmente trabalharemos o plantão psicológico enquanto técnica e o problematizaremos para, em sequência, estudarmos a possibilidade de aplicação da psicanálise ao esquema de plantão psicológico, sustentando nossa tese; e, finalmente, discorreremos brevemente sobre nosso trabalho em plantão psicológico em uma IES.

\section{Plantão Psicológico}

Ao buscar na literatura escritos acerca do plantão psicológico, o que se encontra em sua maioria são artigos e estudos que tratam essa modalidade a partir da psicologia humanista. De acordo com Rebouças e Dutra (2010), Rachel Rosemberg foi a responsável por implantar essa modalidade de atendimento na Universidade de São Paulo, em 1969, e utilizou como referencial a Abordagem Centrada na Pessoa (ACP), de Rogers. Schmidt (2015) afirma que este serviço, ainda ofertado pela universidade, refere-se a um projeto de extensão e que possibilita a prática do aconselhamento psicológico, assim como pesquisas baseadas na ACP. 
Rebouças e Dutra (2010) destacam o Professor Miguel Mahfoud como o primeiro a classificar o plantão como uma modalidade de clínica, sendo assim responsável pela primeira sistematização pública, em 1987. Mahfoud (2012) reitera que o serviço de plantão se refere à disponibilidade de profissionais para atender a demandas não planejadas e muitas vezes única. 0 autor cita como especificidade do plantão a partir do aconselhamento psicológico o ato inicial de acolhimento da demanda a partir da experiência do sujeito onde a direção do processo deve ser definida pelo próprio indivíduo, o que não significa uma passividade do plantonista, mas propicia ao cliente uma organização do pedido de ajuda. Ainda consoante o autor:

Com os poucos recursos de saúde mental atualmente disponíveis à população brasileira, somados à pouca informação a respeito da especificidade e diversidade de cada área profissional envolvida, a tendência tem sido a de que os serviços oferecidos se fixem em algumas prioridades definidas pelos casos mais graves. Uma consequência é a especialização em demandas bastante restritas (Mahfoud, 2012, p. 17).

Dessa forma, entendemos que tal prática surge com o intuito de se adequar às demandas atuais, ou seja, o plantão poderia ser pensado como um atendimento emergencial cujo principal objetivo seria o de acolhimento ao indivíduo no momento de crise (Rebouças \& Dutra, 2010). Desta forma, entende-se que o plantão psicológico é caracterizado como uma nova modalidade clínica. Daher et al. (2017) afirmam que o plantão se caracteriza por uma intervenção que, apesar de possuir local e horário determinados, não depende de um agendamento prévio. Ademais, destaca-se que essa modalidade visa atender a comunidade, além de propiciar aos estudantes de Psicologia, que com ela trabalham, um aprimoramento do manejo clínico.

Rebouças e Dutra (2010) afirmam, então, que:

[...] o plantão psicológico constitui-se como uma prática clínica da contemporaneidade, na medida em que ela promove uma abertura para o novo, o diferente e oferece um espaço de escuta a alguém que apresenta uma demanda psíquica, um sofrimento, oferece um momento no qual esse sujeito que sofre se sinta verdadeiramente ouvido na sua dor (Rebouças e Dutra, 2010, p. 27).

Apesar de a origem do plantão estar vinculada à psicologia humanista, Scorsolini-Comin (2015) estabelece que essa modalidade pode ser vista a partir de diferentes contornos teóricos. 0 autor reitera que o plantão está muito presente nos serviços-escola de psicologia, propiciando um vínculo com a comunidade. A experiência dos autores vem ratificar o que se vislumbra na atualidade como uma emergente demanda de cuidado por parte da população brasileira, sejam cuidados de ordem médica ou psicológica; melhor ainda se forem oferecidos por uma instituição. Rebouças e Dutra (2010) também afirmam que o modelo de atendimento tradicional, de consultórios particulares e sujeitos descontextualizados, de quatro paredes e uma poltrona/divã, 50 minutos uma vez por semana, não mais se adequa às demandas sociais. Muito embora essa afirmação seja passível de importantes críticas, é num contexto social específico que surge, com o intuito de oferecer atendimentos que supram essas procuras, o chamado plantão psicológico.

Ou seja, pensar em um atendimento na modalidade plantão é se inclinar à possibilidade de um atendimento no qual o profissional estará disponível para atendimento de demandas emergentes/urgentes. Nesse sentido, o plantão é a oferta de um espaço de atendimento dito clínico, acessível e imediato; focado na demanda estabelecida pelo paciente e que visa promover a ampliação e avaliação do entendimento do usuário do serviço em relação a suas questões. Desta forma, caberia ao profissional de psicologia se comprometer com a escuta e com o acolhimento deste sujeito que busca ajuda, compreendendo as implicações sociais e psicológicas dos espaços nos quais ele está inserido, bem como as influências mútuas envolvidas no processo de ser-no-mundo (Rebouças \& Dutra, 2010). 


\section{Psicanálise em Plantão: uma Tese Possível}

Brevemente discutido o plantão psicológico, partimos à tentativa de sustentar nossa tese inicial, a lembrar, de que é possível se fazer psicanálise, ou dela se utilizar, nos atendimentos no formato de plantão psicológico. Especificamente, dentro de uma instituição educacional.

Em 1955, Jacques Lacan escreveu, ironicamente, diga-se de passagem, que um tratamento dito psicanalítico é aquilo que faz um psicanalista. Ou seja, para se dizer psicanálise basta que isso - e seja lá o que isso é - seja feito por um psicanalista. Claro fica que ele ironiza a questão justamente para nos dizer em seguida que o problema do que denota ser um tratamento psicanalítico não está no desenho, no formato do tratamento em si, mas na posição que ocupa o analista nesse tratamento (Lacan, 1955/1998c). E a posição que o analista deve ocupar em um tratamento para que esse tratamento seja dito analítico é justamente um lugar, diz-nos Lacan, de ignorância douta. Ignorância que garantiria, pelas circunstâncias do método, com que o sujeito analisante possa enunciar algo de uma fala quiçá verdadeira, para além de toda tentativa superegóica do analista em ser orientativo, curandeiro, psicoterapeuta ou, ainda, atendedor de demandas. Nesse sentido, o analista francês nos explica que o importante nesse encontro entre analista-analisante é que da parte do analista ele esteja inconscientemente alerta para os equívocos enunciados nas sentenças de seu paciente porquanto, naquilo que se escuta, deve prioritariamente, senão exclusivamente, escutar "seu ritmo, seu tom, suas interrupções [e] sua melodia" (Lacan, 1955/1998c, p. 339). Nesse texto, nomeado Variantes do tratamento-padrão, Lacan em lugar algum exclusivisa a psicanálise a um consultório com quatro paredes ou a um tratamento temporalmente constituído, de sujeitos descontextualizados numa poltrona por 50 minutos por semana. A exclusividade da psicanálise, nesse sentido, está circunscrita à escuta ignorante de um analista e, claro, àquilo que surge disso. Afinal, lemos na pena de Lacan, o seguinte:

A questão das variantes da análise, brotando aqui do traço galante de ser ela tratamento- padrão, incita-nos a preservar apenas um critério, por ser ele o único de que dispõe o médico que para elas orienta seu paciente. Esse critério, raramente enunciado, por ser tido como tautológico, nós o escrevemos: uma psicanálise, padrão ou não, é o tratamento que se espera de um psicanalista (Lacan, 1955/1998c, p. 331).

Fato é que Lacan não poderia mesmo enfatizar algo de um tempo cronológico para a denotação de um tratamento psicanalítico. Até porque, dez anos antes, em 1945, ele havia lançado a possibilidade de repensarmos o tempo cronológico a partir da logicidade de três movimentos que constituem a experiência psicanalítica, a lembrar: "o instante do olhar, o tempo para compreender e o momento de concluir" (Lacan, 1945/1998a, p. 204). Com essa virada na técnica, podemos ratificar que o tempo não é bem um problema quando se propõe pensar o que é um tratamento psicanalítico ou, ainda, uma análise. A análise, temporalmente falando, a partir de Lacan, precisa contar com um analista ignorante que direcione o tratamento para um momento onde a urgência de concluir se faça evidente ao analisante para que o sujeito possa escolher sair à sua liberdade.

Aliás, o tempo, além do dinheiro e do divã, estão dentro daquilo que podemos nomear como aspectos técnicos da psicanálise e que, à diferença do método e do arcabouço teórico, obtiveram do próprio Freud a alcunha de modificáveis (Mohr, 2011). Freud, se nos permitirmos uma leve falácia de apelo à autoridade, é categórico em dizer que a técnica que lhe serve encaixa com sua personalidade, muito embora outro analista pudesse se servir de outros instrumentos (Freud, 1912/2017a). Em um texto de 1913, Sobre o início do tratamento, Freud enumera algumas técnicas que utiliza para dar conta de seu objetivo em uma psicanálise, lembrando que essas técnicas ou "regras" deveriam ser tomadas como recomendações, afinal, tais recomendações "precisam extrair sua importância a partir do contexto da estratégia do jogo" (Freud, 1913/2017b, p. 121). Em outras palavras, essas regras, ou técnica, ainda recomendações, devem ser sustentadas pela estratégia, pelo contexto daquela análise em especial; lembrando que a análise é aquilo que 
um analista faz, como já discutimos acima. Dessa maneira, é importante compreender que uma análise em particular, se quisermos sustentar o caso a caso como método freudiano, é o que vai ditar as orientações da técnica, ou das regras. Ainda diz Freud sobre essas regras: "entre elas há determinações que podem parecer diminutas e que provavelmente o são mesmo" (1913/2017b, p. 121).

Enfim, dentre essas diminutas regras, encontramos algumas que servem para pensar a nossa problemática: 1) as entrevistas preliminares como um momento probatório para o analista avaliar se o candidato a analisante pode de fato ser um analisante e, ademais, para que se possa fazer um diagnóstico diferencial, mesmo que temporário; 2) o tempo, cronologicamente estipulado de uma hora; 3) o pagamento pelo serviço, disponibilizado em um tempo específico; e, finalmente, apesar de não abarcar tudo, 4) o divã, o leito como reminiscência de um tempo mítico anterior à construção, criação se desejarem, da psicanálise.

Em resumo, entendemos esses quatro instrumentos como técnicas, as quais o próprio Freud considerou como possivelmente dispensáveis ou permutáveis. Então, poderíamos de fato dizer que "as entrevistas preliminares", "o tempo", "o dinheiro" e "o divã" são dispensáveis para que ocorra uma psicanálise? Se sim, o setting possível, por exemplo, sem divã ou belos quadros da renascença, usados para um plantão psicológico dentro de uma IES pode se enquadrar como adequado a uma análise.

Pensando inicialmente sobre o divã, compreendemos com Freud que ele é um remanescente dos tempos da hipnose e que serviu ao analista para não ser encarado durante as exaustivas horas de trabalho ao longo do dia (Freud, 1913/2017b). Não obstante, o leito analítico, por assim dizer, tem outra serventia bem pontual: "tem a intenção e o efeito de prevenir a mistura imperceptível da transferência com aquilo que ocorre ao paciente, de isolar a transferência e, no tempo certo, deixá-la aflorar como resistência" (Freud, 1913/2017b, p. 135). O divã, ou melhor, a não conexão visual entre analista e analisante serve ao manejo da transferência no sentido de que impede o paciente de se preocupar com as feições do analista e imaginar coisas; e, claro, vice-versa. Contudo, se uma permuta é possível, talvez a questão não seja de fato o divã, ou um leito, mas a elevação da relação imaginária, da imagem, do olhar, para outro lugar. Assim, para aqueles que entendem importante que na realidade, no físico, esse olhar seja impedido, poderiam fazer isso pedindo ao paciente que vire de costas numa sala na qual não cabe um divã, por exemplo; que feche os olhos ou, ainda, que desligue a câmera - lembrando dos nossos tempos e dos atendimentos virtuais coagidos pela pandemia da Sars-CoV-2.

No entanto, seria mesmo necessário um impedimento físico ao olhar para que uma análise seja levada adiante? Ou se trata de outra coisa? Não seria possível alçar a relação da imagem à linguagem sem desviarmos o olhar? Mais, ainda, não poderíamos cogitar que o olhar, ou aquilo que o paciente e analista acreditam ver, poderia, quiçá deveria, ser alçado ao campo de trabalho próprio da psicanálise sem pararmos de nos olharmos? Afinal, é apenas nesse campo, o da linguagem, onde podemos trabalhar; e mais, é apenas ele que existe, afinal, não existe metalinguagem, nos disse Lacan (1966/1998d). Podendo ou não abdicar do olhar, e isso é questão para outro trabalho, fato é que o divã é substituível, e isso nos parece possibilitar a afirmação de que é viável a psicanálise sem ele; até mesmo dentro de uma instituição na qual ele, o leito analítico, por sua vinculação imediata à clínica, não é bem-vindo estamos falando do preconceito escolar/educacional à clínica, mas desta última, falaremos adiante.

Acerca do pagamento, em 1913, Freud o vinculou sobremaneira ao tempo, o que nos permite dizer que, ao menos nesse momento da construção da psicanálise, "tempo é dinheiro". Ou, pelo menos, que um pagamento deve ser realizado pelo tempo disponibilizado. Diz o psicanalista: "quanto ao tempo, sigo exclusivamente o princípio da remuneração por uma determinada hora" (1913/2017b, p. 125). E é isso, no limite: o pagamento é o valor contratado e equivalente pelo serviço prestado. Aristóteles (1991) estaria bem representado, não fosse outra conotação empregada ao dinheiro por Freud e, conseguintemente, pela psicanálise. 0 pagamento é uma metáfora, por assim dizer, para o investimento 
libidinal a ser realizado no tratamento (Freud, 1909/1996b). O dinheiro, instrumento de um deslocamento passível de vinculação retroativa ao pênis e, também ao falo, serve como metáfora do desejo, por assim dizer, em se realizar aquela análise. Mas se for apenas isso, seremos obrigados a compor a lógica de que "quanto mais se paga, mais desejo fazer a análise" e, de outra forma, "se não posso pagar, não desejo essa análise". Bem, entendemos que há diversas maneiras, porquanto metáforas, de se garantir, se isso for possível e necessário, que há desejo em determinada análise. Em outras palavras, o pagar caro não é o exclusivo sinônimo de um desejo por essa ou aquela análise em particular, entendemos que há outras maneiras de se dizer isso. Fato que o dinheiro tem sua importância, seu valor de troca e de uso e que a relação analítica se apropria disso de uma maneira importantíssima, mas no final das contas "o lugar do dinheiro na simbologia é a de ser puro significante, em que a linguagem é sua condição" (Silva \& Henriques, 2019, p. 178). $\mathrm{E}$, para além disso, cabe lembrar como o próprio Freud incentivou certa vez a abertura de lugares de psicanálise para a população em geral (Freud, 1920/1996d). Enfim, entendemos que o pagamento por uma análise pode ser pensado e, inclusive, pode não ter o suporte físico, ou virtual, da moeda. Um atendimento institucional pode ser caro para alguns e completamente vazio para outros. Nesse sentido, convidamos o leitor a recordar o significado de caro para além do seu valor de troca financeira: uma análise cara é uma análise querida, desejada, e seu pagamento pode se dar para além da troca de papéis e moedas. Uma análise pode ser paga, também, com suor, lágrimas e, porque não, sonhos.

Sobre o tempo, bem, se Freud era filho de Cronos - talvez mais por uma organização que o ajudava a cobrar o investimento necessário nas sessões -, Lacan é órfão. Com Lacan, desde 1945, compreendemos que o uso do tempo em uma análise, e em cada sessão, deve ser desenvolvido a partir de uma lógica e, com isso, já não podemos considerar uma sessão de hora fechada ou um tratamento obrigatoriamente crônico e cronologicamente longo como o bom ou verdadeiro tratamento psicanalítico. Assim, com o aporte do tempo dito lógico, entendemos que o plantão psicológico se torna possível de ser compreendido desde a psicanálise e atuado a partir desse local, uma vez que desde essa perspectiva, a do tempo lógico, podemos compreender as questões de uma análise e de uma sessão, a partir da alcunha da urgência. Urgência enquanto coação que convoca necessariamente a um movimento para a sanar ou modificar. Urgência enquanto alerta de algo que precisa ser elaborado e desenvolvido, senão esvaziado. Além disso tudo, ainda vale lembrar das palavras de Lacan, em Função e campo, a nos explicar que o que aparece em uma análise é sempre da ordem da urgência e que precisa ser tratado logicamente para que possa ser concluído: "nada há de criado que não apareça na urgência, e nada na urgência que não gere sua superação na fala" (Lacan, 1953/1998b, p. 242). Que possamos aprofundar a análise dessa citação ao compreender a importância da fala dentro do campo da linguagem, o único campo analítico. É desde a fala que uma urgência pode ser superada, o que reforça o que discutimos acima sobre o uso do divã; lembremos: o que importa é a função e o uso da fala em psicanálise. Ratifica o autor:

[...] nada há, tampouco, que não se torne contingente nela [na fala], quando chega para o homem o momento em que ele pode identificar numa única razão o partido que escolhe e a desordem que denuncia, para compreender sua coerência no real e se antecipar, por sua certeza, à ação que os coloca em equilíbrio (Lacan, 1953/1998b, p. 242).

Finalmente, a questão das entrevistas preliminares e seu uso de elaboração diagnóstica. Para nos aprofundarmos neste tema, iremos antes percorrer outra questão, o problema do método.

Acima, dissemos que a discussão sobre a psicanálise em plantão psicológico perpassa a técnica psicanalítica - brevemente discutida -, o método e a teoria. Essa última, cabe dizer que a consideramos como o arcabouço científico construído indutivamente desde a clínica freudiana e, em sequência, por aqueles que deram continuidade, cada um a seu modo e de diferentes lugares científicos, na psicanálise. Não entraremos muito nesses detalhes, 
pois a teoria em si não implica uma proibitiva da extensão da psicanálise ao plantão psicológico. Mas nos interessa, sobremaneira, pensar seu método.

O método psicanalítico é, senão caudatário, filiado ao que chamamos de método clínico. Um método de investigação por excelência, indutivo por nascimento e que recebe nas ciências médicas, por assim dizer, seu lugar de destaque. O método clínico é um método indutivo porque pressupõe o debruçamento do pesquisador sobre um caso, ou um conjunto de casos, para, posteriormente, construir hipóteses e leis gerais de funcionamento daquilo que foi estudado. Por meio dele, constroemse generalizações a partir do estudo de particulares. O método clínico, ainda, pode ser entendido a partir de quatro componentes, a saber: semiologia; etiologia; diagnóstica; e, terapêutica (Dunker, 2011). Para que o método possa de fato ser descrito como clínico, diz-nos Dunker, são necessárias "duas propriedades fundamentais: a homogeneidade entre seus elementos e a covariância de suas operações" (Dunker, 2011, p. 422). Ou seja, deve haver no trabalho clínico, para que ele seja considerado clínico, a covariância das operações, seus componentes, da etiologia, semiologia, terapêutica e diagnóstica; assim também é fundamental que entre seus elementos exista homogeneidade, isto é: uma doença cuja causa é orgânica deve ter componentes orgânicos para seu entendimento, deve ser diagnosticada por meio desses signos orgânicos e ter uma proposta terapêutica que não fuja disso, o orgânico.

Dessarte, como a questão da clínica se vincula às entrevistas preliminares e sustenta nossa tese? Dunker nos diz que a diagnóstica é a "operação chave da clínica, pois dela dependem todas as outras operações. Podemos dizer que o diagnóstico, como reconhecimento do sintoma é o ato elementar da clínica" (2011, p. 421); já Freud afirmou que se utilizava das entrevistas preliminares para entender o caso e, por conseguinte, realizar um diagnóstico diferencial (1913/2017b). Cabe ressaltar que Dunker vai distinguir dois tipos de diagnósticos, o diferencial e o evolutivo; esse último sendo vinculado à possibilidade de manejo e reformulação, intrínseca à toda diagnóstica quando se trata do método clínico (2011). Enfim, ao associar as propostas dos autores, compreendemos que são as entrevistas preliminares que nos possibilitam realizar um diagnóstico diferencial e propor uma terapêutica sustentada em uma semiologia que possibilita uma etiologia.

Pois bem, se as entrevistas preliminares são uma parte da técnica psicanalítica, uma parte que nos serve à realização de um diagnóstico diferencial, pode-se dizer que um plantão psicológico, que se utiliza da psicanálise, é como entrevistas preliminares? Mais: seria possível dizer que isso que ocorre num plantão psicológico embasado na psicanálise, é uma análise?

Entendemos que afirmar o que ocorre em um plantão psicológico como uma análise seria um tanto arriscado porquanto precisaríamos explorar todos os problemas aqui elencados de maneira mais aprofundada. Não obstante, 1) se uma análise é o que faz um analista, 2) que não precisa necessariamente seguir à risca os elementos técnicos e míticos estipulados desde o início da psicanálise, mas 3) deve estar atento à teoria e 4) seguindo o método clínico; além disso, 5) entendendo que o plantão psicológico em psicanálise serve como entrevistas preliminares a fim de um diagnóstico, mas não esquecendo que, se levarmos ao limite o tempo lógico, 6) uma análise pode ocorrer em um curto espaço de tempo e, quiçá, em uma única sessão, então talvez nossa tese possa ser sustentada.

Ademais, cabe ainda discutirmos brevemente sobre uma regra que devemos encaixar na ordem da exceção: a chamada regra fundamental da psicanálise, a associação livre. Entendemos que ela é uma exceção no sentido de que ela faz parte dos itens essenciais, contudo, parece-nos que ela é mais da ordem do método do que da técnica; lembremos que o método clínico se trata de um debruçar-se sobre um caso particular para, dele, somado a outros particulares, construir-se teoria. Dessa forma, compreendemos por ora a associação livre, e seu correlato, a atenção flutuante, como regras metodológicas, distintas das regras técnicas. A associação livre e a atenção flutuante compõem o método porquanto são a base dele, a base da posição investigativa do psicanalista; sem esses pressupostos metodológicos, não há investigação, tampouco um debruçar-se. 
Por fim, cabe recordar que conjecturamos a tese de que a psicanálise pode sim ser utilizada como arcabouço teórico, técnico e metodológico para um plantão psicológico e, por ora, entendemos possível ratificá-la. Ademais, não pretendemos ao início desse trabalho igualar uma análise àquilo que pode ocorrer em um plantão psicológico, o que demandaria um trabalho maior, mas nossos estudos nos levaram à possibilidade de dizer que a psicanálise pode ser utilizada num plantão psicológico sem termos a necessidade de nos servirmos de uma "psicologia holística"; e isso porque os componentes da clínica, e, portanto, da clínica psicanalítica - semiologia, etiologia, diagnóstica e terapêutica -, podem ser pensados em um tempo lógico. E suas regras possuem, desde Freud, certa maleabilidade.

\section{O Âmbito Escolar/Educacional}

Elucidadas as diretrizes teóricas sobre possibilidades e impossibilidades do exercício do plantão a partir da psicanálise, concordamos com a necessidade de expor um detalhamento prático desta experiência e como, em nuances diárias, a teoria toma forma no encontro entre profissional e paciente.

A primeira questão a qual podemos discorrer é: que benefício este tipo de exercício oferece aos alunos de uma IES? Já vimos que o plantão surgiu nos moldes de aconselhamento psicológico e acolhimento, e a psicanálise, por sua vez, utilizase da associação livre e de uma escuta que por ora podemos nomear clínica. Como se dá ou como se pode averiguar, então, a eficácia do serviço proposto? Bem, inicialmente seria um grande equívoco afirmar que, em todas as sessões, em todo atendimento, consegue-se os mesmos efeitos nos pacientes e, ainda, que se assemelham em forma e conteúdo, afinal da mesma maneira como acontece em uma análise ou uma terapia, cada caso é único e deve ser tratado como tal. Talvez o grande desafio dessa proposta seja exatamente esse, não há o que esperar - apesar do estudante sempre esperar algo - tanto a nível de demanda, quanto de resultado.

Não é raro perceber na postura do paciente, após 20 ou 30 minutos de sessão, uma mudança na postura corporal, ritmo e tonalidade da fala acompanhadas de um "ufa", um alívio que podemos relacionar ao uso da fala como motilidade para uma descarga energética (Freud, 1900/1996a). Muitos estudantes esperam que o atendimento se configure enquanto aconselhamento psicológico e buscam respostas e soluções para suas questões, o que pode muitas vezes gerar um sentimento de frustração em relação ao trabalho realizado; em alguns casos, por outro lado, consegue-se minimamente repensar essas demandas e se reposicionar diante delas pelo questionamento. Em decorrência da brevidade do atendimento de plantão e de sua característica pontual, os resultados esperados não ambicionam uma cura - ademais, cabe dizer que a própria ideia de cura em psicanálise é passível de questionamento -, terapia, muito menos a resolução pura e simples da demanda apresentada. Entretanto, não se deve menosprezar o potencial reorganizador da fala, o efeito re-historicizador de uma escuta analítica. $\mathrm{O}$ analista (se é que podemos chamar assim esse "atendente") que realiza atendimentos de plantão psicológico se apoia, portanto, no trabalho de escuta e, ainda, na promoção de um espaço de possibilidade de fala dita livre, propriamente associação livre enquanto método de trabalho, e o questionamento do sintoma como ele se apresenta, a fim de que ao paciente seja possível repensá-lo, minimamente que seja.

Há possibilidades de se realizar um atendimento de 60 minutos, ou 15, em salas diferentes, com ou sem uma mesa a separar as cadeiras, com aperto de mão como cumprimento, um abraço, um sorriso, ou nenhum dos anteriores. Há choro, riso, exigências de soluções rápidas e, às vezes, um "de que isso serviu?" [sic]. A procura por serviços de saúde mental ocorre por inúmeras motivações e, muitas vezes são carentes de atendimento duradouro, multiprofissional e especializado. Nesse sentido, o plantão também serve como uma alternativa acessível e rápida de chegar a esses serviços, atuando com o encaminhamento dos casos para instituições e profissionais que ofereçam um atendimento outro.

Outra questão que surge ao pensarmos a psicanálise em plantão psicológico é referente à transferência, uma ferramenta essencial para 
o exercício da psicanálise. Como pensá-la num atendimento único, breve, ou sem o conhecimento por parte do paciente de quem o irá atender? 0 trabalho escolar/educacional tem como característica um vínculo institucional pré-estabelecido entre os alunos e a IES, e entre o psicólogo e a IES; ou seja, há um terceiro na relação: aluno - IES - psicólogo. Então, isso que acontece entre aluno e psicólogo num atendimento em âmbito educacional, pode ser pensado desde a transferência? Se sim, de qual maneira? Vale recordar que Freud sempre atribuiu a transferência à neurose e não ao vínculo analítico, tampouco ao setting. A transferência é uma característica da neurose, ou seja, ela ocorre independente do lugar ou de como esse encontro se estabelece (Freud, 1917 [1916-17]/1996c). Tudo bem que lugares e encontros distintos possam oferecer maiores ou menores resistências, tais ou quais características transferenciais, mas o fato é que a transferência ocorre independente do onde. Costumamos entender esse aspecto da análise, a transferência, em um âmbito educacional como que acontecendo a partir de um lugar emprestado, não obstante um lugar. Até porque, a recordar o que disse Lacan sobre a transferência em sua lição de 19 de dezembro de 1956, entendemos que a estrutura transferencial é da ordem discursiva, simbólica, daquilo concernente à relação de um sujeito com o Outro. Aliás, diz o autor:

O Outro não é simplesmente o outro que está ali, mas literalmente o lugar da palavra. Existe, já estruturado na relação falante, este mais-além, este Outro para além do outro que vocês apreendem imaginariamente, este Outro suposto que é o sujeito como tal, o sujeito em que a fala de vocês se constitui, porque ele pode, não somente acolhê-la, percebê-la, mas também responder a ela. É sobre esta linha $[A \rightarrow S]$ que se estabelece tudo o que é da ordem transferencial, o imaginário desempenhando aí, precisamente, um papel de filtro, até mesmo de obstáculo (Lacan, 1956-57/1995, p. 79-80).

O psicólogo empresta o lugar imaginário de "psicólogo da instituição" para poder iniciar seu efeito na relação com o estudante, um empréstimo que é rapidamente recuperado, porquanto no final das contas, ele ocupa esse lugar da palavra, lugar do Outro. O "psicólogo da instituição" pode até fazer parte desse filtro, obstáculo transferencial, mas que logo é reorganizado como podemos ver nos casos de estudantes que retornam ao plantão psicológico com a condição de serem atendidos exclusivamente por aquele um que outrora o escutou. Não adianta outro "psicólogo da instituição", só serve aquele com o qual certa transferência começou a ser desemprestada do lugar institucional.

Por fim, cientes de que esse recorte de nossa prática poderia ser mais esmiuçado, apesar dos propósitos deste artigo não compreender tal tarefa, ressaltamos que muitos contatos/atendimentos realizados no formato de plantão ficam restritos a uma orientação, encaminhamento ou tentativa de acolhimento de demanda; não obstante há aqueles que estabelecem uma transferência importante e topam desorganizar lugares e se reorganizar na linguagem que os habitam. A esses encontros, segundo a tese que ora sustentamos, ousamos alcunhar como uma psicanálise.

\section{Considerações Finais}

O surgimento do plantão psicológico está atrelado à abordagem centrada na pessoa, proposta por Rogers, mais especificamente ao aconselhamento psicológico. No entanto, dentre os critérios que caracterizam um atendimento como plantão estão a promoção de um espaço de escuta o qual não necessita agendamento prévio e que muitas vezes pode ocorrer somente em um encontro. No atendimento de plantão ocorre um encontro na urgência, o qual se desenvolve a partir de uma escuta. Vimos com Lacan que o encontro entre analista e analisante pode ser pensado como um evento que acontece a partir de um analista inconscientemente alerta a equívocos enunciados nas sentenças de seu paciente e, vimos também que Freud propõe técnicas para um atendimento psicanalítico; técnicas essas que em um primeiro momento poderiam não se enquadrar dentro da modalidade de plantão. Não obstante, discutimos como o pai da psicanálise 
não define tais regras enquanto essenciais, todavia cabendo ao método certa indispensabilidade. Desta forma, sustentamos a possibilidade de um plantão a partir da psicanálise, pois entendemos que uma análise é o que um analista faz a partir de um método particular de prática, muito embora não seja necessário seguir à risca as técnicas/regras estipuladas como que miticamente. Outrossim, o plantão pode ser equiparado às entrevistas preliminares, ao possibilitar a elaboração de um diagnóstico diferencial e a proposta de uma terapêutica.

Outro ponto que ainda abordamos brevemente é o plantão psicológico dentro de uma IES. O plantão psicológico na sua origem está atrelado às universidades sendo vinculado ao curso de Psicologia de forma a proporcionar aos alunos a prática clínica, como também uma alternativa para a comunidade. $\mathrm{A}$ IES da qual surgenossa experiência nãopossuio cursode Psicologia, não obstante destina vagas de estágio para alunos de outras instituições. No que tange à ligação com a comunidade, o Núcleo de Acompanhamento discente da instituição, desde 2008 oferece serviços à comunidade acadêmica, sendo um deles o de plantão psicológico. É nesse contexto, portanto, que podemos recortar e ratificar que o trabalho em plantão psicológico, a partir da psicanálise, tem surtido efeitos terapêuticos importantes em alguns casos; em outros tem possibilitado ao indivíduo-estudante organizar algo de sua vida acadêmica; alguns outros dão início a processos de análise pessoal em outros ambientes, na maioria das vezes encaminhados pelo próprio setor.

A partir da experiência dos autores percebemos a importância dos espaços de escuta qualificada oportunizados pelo plantão psicológico. $O$ encontro que ocorre, possibilitando a criação de um vínculo transferencial (que, por ser institucionalizado, possui certas distinções que não cabe neste trabalho esmiuçar), enseja um diagnóstico diferencial que indica uma terapêutica. Terapêutica que, por vezes, pode ser percorrida no próprio espaço de plantão, por outras precisa ser encaminhada para outros lugares sociais. Portanto, e concluindo, compreendemos que é possível que a psicanálise se aproprie dessa modalidade a partir de seu arcabouço teórico, técnico e metodológico.

\section{Contribuição}

Os pesquisadores declaram não haver conflitos de interesse.

\section{Referências}

Aristóteles. (1991). Ética a Nicômaco. Nova Cultural.

Daher, A. C. B., Ortolan, M. L. M., Sei, M. B., \& Victrio, K. C. (2017). Plantão psicológico a partir de uma escuta psicanalítica. Semina: Ciências Sociais e Humanas, 38(2), 147-158. https://doi. org/10.5433/1679-0383.2017v38n2p147.

Dunker, C. I. L. (2011). Estrutura e constituição da clínica psicanalítica: uma arqueologia das práticas de cura, psicoterapia e tratamento. Annablume.

Freud, S. (1996a). A Interpretação dos Sonhos W. I. de Oliveira, Trad.). In. J. Salomão (Ed.). Obras psicológicas completas de Sigmund Freud: edição standard brasileira (Vol. 5). Imago (Trabalho originalmente publicado em 1900).

Freud, S. (1996b). Notas sobre um caso de neurose obsessiva (J. O. de A. Abreu, Trad.). In. J. Salomão (Ed.). Obras psicológicas completas de Sigmund Freud: edição standard brasileira (Vol. 10). Imago (Trabalho originalmente publicado em 1909).

Freud, S. (1996c). Conferência XXVII Transferência (J. L. Meurer, Trad.). In J. Salomão (Ed.). Obras psicológicas completas de Sigmund Freud: edição standard brasileira (Vol. 16). Imago (Trabalho originalmente publicado em 1917).

Freud, S. (1996d). Dr. Anton von Freund (E. A. M. de Souza, Trad.). In J. Salomão (Ed.). Obras psicológicas completas de Sigmund Freud: edição standard brasileira (Vol. 18). Imago (Trabalho originalmente publicado em 1920).

Freud, S. (2017a). Recomendações ao médico para o tratamento psicanalítico (C. Dornbusch, Trad.). In. G. Iannini (Ed.). Fundamentos da clínica psicanalítica. (Obras incompletas de Sigmund Freud). Autêntica (Trabalho originalmente publicado em 1912). 
Freud, S. (2017b). Sobre o início do tratamento

(C. Dornbusch, Trad.). In G. Iannini (Ed.).

Fundamentos da clínica psicanalítica. (Obras incompletas de Sigmund Freud). Autêntica

(Trabalho originalmente publicado em 1913).

Lacan, J. (1995). O seminário, livro 4: a relação de objeto. J. Zahar.

Lacan, J. (1998a). O tempo lógico e a asserção de certeza antecipada (V. Ribeiro, Trad.). In. J. Lacan. Escritos. J. Zahar (Trabalho originalmente publicado em 1945).

Lacan, J. (1998b). Função e campo da fala e da linguagem em psicanálise (V. Ribeiro, Trad.). In. J. Lacan. Escritos. J. Zahar (Trabalho originalmente publicado em 1953).

Lacan, J. (1998c). Variantes do tratamento-padrão (V. Ribeiro, Trad.). In. J. Lacan. Escritos. J. Zahar (Trabalho originalmente publicado em 1955).

Lacan, J. (1998d). A ciência e a verdade (V. Ribeiro, Trad.). In. J. Lacan. Escritos. Rio de Janeiro: Zahar (Trabalho originalmente publicado em 1966).

Mahfoud, M. (2012). A vivência de um desafio: plantão psicológico. In M. Mahfound. (Org.). (2012). Plantão Psicológico: novos horizontes. Companhia llimitada.

Mohr, A. M. (2011). Aquém dos ideais da educação ou das (im)possibilidades do trabalho do psicanalista em atendimento individual na escola [Dissertação de Mestrado, Universidade Federal do Paraná].

Rebouças, M. S. S., \& Dutra, E. (2010). Plantão Psicológico: uma Prática Clínica da Contemporaneidade. Revista da Abordagem Gestáltica: Phenomenological Studies, 16(1), 19-28. https://www.redalyc.org/articulo. oa?id=3577/35773561304

Schmidt, M. L. S. (2015). Aconselhamento psicológico como área de fronteira. Psicologia USP, 26(3), 407-413. https://doi. org/10.1590/0103-656420140033.

Scorsolini-Comin, F. (2015). Plantão psicológico e o cuidado na urgência: panorama de pesquisas e intervenções. Psico-USF, 20(1), 163-173. https://doi.org/10.1590/141382712015200115
Silva, N. O. da, \& Henriques, R. da S. P. (2019). O estatuto psíquico do dinheiro à luz da teoria psicanalítica. Ágora, 22(2), 173-179. https:// doi.org/10.1590/1809-44142019002004 